\title{
The Importance of Culture in Childbearing
}

By: Lynne Lewallen

\section{This is the accepted version of the following article:}

Lewallen, L.P. (2011). The importance of culture in childbearing. Journal of Obstetric, Gynecologic, \& Neonatal Nursing, 40 (1), 4-8. doi: 10.1111/j.1552-6909.2010.01209.x,

which has been published in final form at http://dx.doi.org/10.1111/i.15526909.2010.01209.x

***@ Wiley \& Association of Women's Health, Obsteric and Neonatal Nurses (AWHONN). Reprinted with permission. No further reproduction is authorized without written permission from Wiley. This version of the document is not the version of record. Figures and/or pictures may be missing from this format of the document. $* * *$

\section{Abstract:}

In 1972, Mary Lou Moore wrote about the importance of nurses in the United States becoming aware of childbirth traditions of other countries. In 2010, North America has become more culturally diverse, and the dominant culture related to childbirth has become the hospital culture. Nurses must acknowledge this unique culture and work to make women of all cultures comfortable in this setting to ensure a safe and satisfying childbearing experience.

Keywords: Nursing | Childbirth | Prenatal care | Neonatal care | Culture

\section{Article:}

In 1972, Dr. Mary Lou Moore wrote about the importance of considering a woman's culture when caring for her and her family during labor. Dr. Moore described several cultural groups outside of North America, contrasting their typical labor experiences and pregnancy-related beliefs with those of women in North America. She also noted that nurses in North America needed to become aware of other cultural traditions to assist women during childbearing and use teachable moments during everyday encounters with families to influence women and children to adopt progressive ideas of childbearing. Her advice for nurses to become aware of birth traditions in various cultures is even more salient today.

Culture can be defined as "integrated patterns of human behavior that include the language, thoughts, communications, actions, customs, beliefs, values, and/or institutions of racial, ethnic, religious, and/or social groups" (Lipson \& Dibble, 2005, p. xi). Childbearing has always been rooted in culture. Although childbirth occurs in every culture, in each culture there are unique meanings and customs associated with pregnancy, childbirth, and the puerperium. In the past 40 years, North America has become more multicultural, with many recent immigrants. Because of this multiculturalism, the only "common" culture of childbearing in North America is the 
hospital culture. Most babies in North America are born in the hospital (Canadian Institute for Health Information, 2004; MacDorman \& Menaker, 2010), and since 1972, the typical childbearing woman and the health care system culture of childbearing have changed dramatically.

In the 1970s, the United States was comprised 88\% White and 22\% other races (U.S. Bureau of the Census, 1974), and Canada had a similar makeup (Dominion Bureau of Statistics, 1975). In the first decade of the 21st century, the United States and Canada have become more diverse, and the percentage of Whites is now $80 \%$ in the United States (Statistical Abstract of the United States, 2010) and 66\% in Canada (Central Intelligence Agency, 2010). Among women of childbearing age, the population is even more diverse. In 1970, 83\% of births in the United States were to White women (U.S. Bureau of the Census); whereas in 2006, this rate had decreased to 78\% (Martin et al., 2009). Canada does not report the race of newborns or their mothers in their vital statistics, but the race of Canadian newborns likely mimics their population diversity. The rate of Cesarean deliveries in the United States is now 32\% and has been rising rapidly since 1996 (Menacker \& Hamilton, 2010), and in Canada it is more than 24\% (Canadian Institute for Health Information, 2006). Along with the increase in operative deliveries, there has been a concomitant increase in medical intervention during labor in the form of epidural anesthesia, and labor induction with oxytocin, both of which make it more likely that additional medical interventions will be needed.

\section{Who are Our Patients in the 21st Century?}

In the 1970s, large cities in North America were multicultural, but rural areas often were not. This is no longer true. Even the most remote areas in North America often contain a mix of cultures, and many include recent immigrants, some legally in the country and some not (Tankersley \& Parsons, 2008). Recent immigrants may not have family members nearby to help them through the developmental crisis of pregnancy and childbirth, and families who have immigrated illegally may experience additional stresses related to fear of deportation. Up to 31\% of foreign-born people living in the United States are undocumented, having either illegally entered the country or stayed beyond their visas (Hoefer, Rytina, \& Campbell, 2007). Some immigrant families report not using public health care agencies for fear of immigration information being shared with authorities. Instead, they rely on family and friends for health care advice or home remedies (Hagan, Rodriguez, Capps, \& Kibiri, 2003). Further, recent immigrants may not receive adequate prenatal care due to financial issues, beliefs that medical care is only necessary during illness, or other reasons. Upon arrival to the hospital for birth, women may be hesitant to challenge the hospital culture because of language barriers, cultural respect for authority figures, or lack of knowledge. As a result, families may be overwhelmed by the birth experience and may not feel that they are able to retain any control.

The racial makeup of the population of North America has changed dramatically in the past 40 years. 
However, the opposite scenario can also occur. In the early to mid-20th century, immigrants frequently immersed themselves in the dominant culture and took on many of the characteristics of that culture within one generation (Hirschman, 2005). This trend, however, may be changing. With the growing diversity in North America often has come a celebration of that diversity. For example, many people identify themselves with the culture of their heritage and the culture of their residence and show this by referring to themselves as both, e.g., Asian Americans. Even when families identify themselves with a general heritage, such as Asian, it is important to remember that many subcultures exist that may differ significantly from each other in cultural traditions (Lipson \& Dibble, 2005). Even within subcultures, beliefs can differ within communities, and factors such as immigration experiences can result in changes in traditional cultural beliefs and practices (Grewal, Baghat, \& Balneaves, 2008). Embracing their culture of heritage, some families present to the hospital for birth with firm expectations about the childbirth experience that may conflict with hospital routines and health care provider preferences. Additionally, expectations of prenatal and neonatal care may vary among women and their health care providers. When health care expectations vary, women and their families may be labeled as "noncompliant," or in the case of behaviors such as drug use, be subject to legal action for providing inadequate care for their unborn children or newborns (Flavin \& Paltrow, 2010).

\section{What is Prenatal Care Like in the 21st Century?}

Regular prenatal care is purported to improve birth outcomes, although rates of low birth weight and prematurity have risen, and many of the tests and routines that have been recently added to the prenatal care regimen are not evidence based but based instead on expert opinion (Novick, 2004). In the United States, all women are expected to follow a prescribed regimen for number of visits and content of prenatal care (Hanson, VandeVusse, Roberts, \& Forristal, 2009). Women who do not follow these guidelines are often said to have inadequate prenatal care and may be labeled as "at risk" upon their entrance to the hospital for childbirth. Some women of ethnic minority have reported dissatisfaction with prenatal care related to cultural stereotyping (Novick, 2009).

One cultural group that may not follow the standard guidelines for prenatal care is Mexican Americans. Some recently arrived Mexican American women may be illegal immigrants and fear detection if they present to clinics; some may lack access to transportation; and some may feel that pregnancy, being a natural part of life, requires no special health care as long as the woman feels healthy (Lipson \& Dibble, 2005). Indeed, Mexican Americans may be the least acculturated immigrant group in the United States, and Mexican American women are less likely to receive prenatal care and less likely to take their infants for well-child care than other immigrants (Callister \& Birkhead, 2002).

Despite this, they often have better birth outcomes and health status than other immigrants, which has been termed the "Hispanic paradox," and the more acculturated the population 
becomes, the more negative health behaviors are reported (Page, 2007). Positive cultural health practices are thought to be part of the reason for healthy birth outcomes (Callister \& Birkhead), which illustrates that positive cultural health practices should be supported, even if women do not necessarily comply with health system protocols. However, care should be taken not to assume homogeneity of any cultural group, as health practices can vary widely within each culture (Fleuriet, 2009). Newer proposed models of prenatal care such as CenteringPregnancy incorporate opportunities for group interaction and for discussion of issues important to the small group of women present that day, instead of only provider-directed discussion (Reid, 2007). This can potentially facilitate more culturally-sensitive care.

Immigrant families do not use public health care agencies for fear of immigration information being shared with authorities.

\section{What Are Our Hospital Maternity Units Like in the 21st Century?}

In North America, even though health care providers say that pregnancy is a healthy time and birth is a natural experience, care is oriented toward interventions and the risk of potential complications. The typical woman's experience on the maternity unit begins with the assumption that childbearing is risky and things can go wrong. Nursing care is geared toward minimizing pain and risk. External forces that affect nursing care in maternity units include the nursing shortage, which may result in inadequate staffing levels, and the high litigation rate for obstetric cases (Jonsson, Norden \& Hanson, 2007), which can decrease the tolerance for letting labor progress naturally.

Certain routines in most North American maternity units may seem odd to families who are unfamiliar with the hospital culture. Most hospitalized women have restricted food intake during labor, so culturally prescribed foods are discouraged. Nearly 25\% of Canadian women (Canadian Institute for Health Information, 2006) and up to as many as $60 \%$ of American women (Osterman, Martin, \& Menacker, 2009) have epidural or spinal anesthesia for labor and delivery. Electronic fetal monitors, which can impede movement, are considered standard care. Intravenous fluids are routinely administered. Many of these interventions confine a woman to her bed, and the inactivity can negatively affect natural labor. More than $20 \%$ of women in North America have their labor induced (Canadian Institute for Health Information, 2010; Zhang, Joseph, \& Kramer, 2010), and many of these women are administered oxytocin for induction or labor augmentation, which causes contractions to be more frequent and more intense than natural labor. The fetal membranes are frequently artificially ruptured during labor induction, which increases the pressure for birth to occur within 24 hours to reduce the risk of infection. This may lead to an early decision for a Cesarean and/or instrumentation for birth. These interventions during labor and birth may make early breastfeeding more difficult, either due to mother immobility/pain or infant grogginess.

\section{What Is Neonatal Care Like in the 21st Century?}


In the United States, children are typically immunized against 13 diseases in their first 18 months of age, requiring several, carefully spaced, health care visits. If immunizations are not received according to schedule, children may be prohibited from attending public school (Womack, 2010). Besides immunizations, other health screening is recommended during well-child visits. Many children do not attend all the recommended visits, and the lowest rates of compliance are among Black and Hispanic children 0 to 5 years of age (Selden, 2006). Individuals from some cultural groups may be unlikely to participate in regular health screening because they aren't convinced of its importance or only believe that health care should be sought if symptoms of illness are present. For example, American Indians may not participate in clinic visits if they or their children are healthy and may be skeptical of medical treatments or procedures if they are not convinced of their usefulness (Lipson \& Dibble, 2005). Nurses working with parents of infants should clearly explain rationales for neonatal care procedures and routines and be open to learning about and discussing unique cultural health-promoting practices.

\section{What Is the Nursing Role in the Care of Women of All Cultures?}

Women not accustomed to this culture of potential risk in prenatal care, childbirth, and neonatal care may be frightened, overwhelmed, or made to feel guilty if they are not willing to undergo some of the expected interventions. This also is an issue for acculturated North Americans who believe pregnancy is healthy and birth should be natural, but it may be more of an issue for women who are recent immigrants, especially if they do not speak fluent English. American nurses are so accustomed to our childbirth culture that we are in danger of forgetting that it is a foreign land to the women and families we care for.

Nurses must acknowledge that the maternity health care system has a unique culture that may clash with the cultures of many of our clients.

Nurses have an important role as cultural brokers as we welcome women and their families into our workplaces where we share one of the most intimate experiences of their lives. First, we must acknowledge that the maternity health care system has a unique culture that may clash with the cultures of many of our clients. We should thoroughly explain procedures and offer clear rationales for them. When choices exist, we should offer them, and when women and their families make choices that we do not agree with, we should attempt to see the situation from their vantage points. As maternity nurses, we have a responsibility to be aware of the childbirth traditions of the groups who live in our neighborhoods. Nurse educators should offer frequent updates to staff on cultural traditions related to childbirth and provide opportunities to discuss how these traditions should be incorporated into nursing care. Representative members of cultural groups can provide valuable consultation when policies are being developed so that traditions may be honored.

Our major role as nurses is to provide safe and evidence-based care to promote optimal birth outcomes for all women. We need to remember there is more than one way to provide this care. 
Nurses are educated to assess every woman as an individual and to plan care with mutual goal setting for the best outcomes. By assisting all clients to understand our culture of childbirth, and by amending our practices as much as possible to embrace the cultural traditions of others, we will enhance the childbearing experience and promote the health of women, newborns, and families.

\section{REFERENCES}

Callister, L. C., \& Birkhead, A. (2002). Acculturation and perinatal outcomes in Mexican immigrant childbearing women: An integrative review. Journal of Perinatal \& Neonatal Nursing, 16 (3), 22-38.

Canadian Institute for Health Information. (2004). Giving birth in Canada: Providers of maternity and infant care. Ottawa, ON: Author.

Canadian Institute for Health Information. (2006). Giving birth in Canada: The costs. Ottawa, ON: Author.

Central Intelligence Agency. (2010). World fact book: Canada. Retrieved from https://www.cia.gov/library/publications/the-world-factbook/geos/ca.html

Dominion Bureau of Statistics. (1975). Canada year book, 1975. Ottawa, ON: Author.

Flavin, J., \& Paltrow, L. M. (2010). Punishing pregnant drug-using women: Defying law, medicine, and common sense. Journal of Addictive Diseases, 29 (2), 231-244. doi: 10.1080/10550881003684830.

Fleuriet, K. J. (2009). Problems in the Latina paradox: Measuring social support for pregnant immigrant women from Mexico.Anthropology \& Medicine, 16 (1), 49-59.

doi: 10.1080/13648470802425989.

Grewal, S. K., Baghat, R., \& Balneaves, L. G. (2008). Perinatal beliefs and practices of immigrant Punjabi women living in Canada.Journal of Obstetric, Gynecologic, \& Neonatal Nursing, 37, 290-300. doi: 10.1111/j.1552-6909.2008.00234.x.

Hagan, J., Rodriguez, N., Capps, R., \& Kibiri, N. (2003). The effects of recent welfare and immigration reforms on immigrants' access to health care. International Migration Review, 37 (2), 444-463.

Hanson, L., VandeVusse, L., Roberts, J., \& Forristal, A. (2009). A critical appraisal of guidelines for antenatal care: Components of care and priorities in prenatal education. Journal of Midwifery \& Women's Health, 54 (6), 458-468. doi: 10.1016/j.jmwh.2009.08.002.

Hirschman, C. (2005). Immigration and the American century. Demography, 42 (4), 595-620. doi: 10.1353/dem.2005.0031. 
Hoefer, M., Rytina, N., \& Campbell, C. (2007). Estimates of the unauthorized immigrant population residing in the United States: January 2006. Office of Immigration Statistics, Policy Directorate, U.S. Department of Homeland Security. Retrieved fromhttp://www.dhs.gov/xlibrary/assets/statistics/publications/ill_pe_2006.pdf

Jonsson, M., Norden, S. L., \& Hanson, U. (2007). Analysis of malpractice claims with a focus on oxytocin use in labour. Acta Obstetricia et Gynecologica, 86, 315-319. doi: 10.1080/00016340601181318.

Lipson, J. G., \& Dibble, S. L. (Eds.). (2005). Culture \& clinical care. San Francisco, CA: UCSF Nursing Press.

MacDorman, M. F., \& Menaker, F. (2010). Trends and characteristics of home and other out-ofhospital births in the United States, 1990-2006. National Vital Statistics Reports, 58(11). Hyattsville, MD: National Center for Health Statistics. Retrieved from http://www.cdc.gov/nchs/data/nvsr/nvsr58/nvsr58_11.pdf

Martin, J. A., Hamilton, B. E., Sutton, P. D., Ventura, S. J., Menacker, F., Kirmeyer, S., \& Mathews, T. J. (2009). Births: Final data for 2006. National Vital Statistics Reports, 57 (7). Retrieved from http://www.cdc.gov/nchs/data/nvsr/nvsr57/nvsr57_07.pdf

Menacker, F., \& Hamilton, B. E. (2010). Trends in cesarean delivery in the United States (NCHS Data Brief, no 35). Hyattsville, MD: National Center for Health Statistics.

Moore, M. L. (1972). The importance of culture in childbearing. Journal of Obstetric, Gynecologic, \& Neonatal Nursing, 1 (2), 29-32.

Novick, G. (2004). CenteringPregnancy and the current state of prenatal care. Journal of Midwifery \& Women's Health, 49 (5), 405-411. doi: 10.1016/j.jmwh.2004.06.001.

Novick, G. (2009). Womens' experience of prenatal care: An integrative review. Journal of Midwifery \& Women's Health, 54 (3), 226-237. doi: 10.1016/j.jmwh.2009.02.003.

Osterman, M. J. K., Martin, J. A., \& Menacker, F. (2009). Expanded health data from the new birth certificate, 2006. National Vital Statistics Reports, 58(5). Hyattsville, MD: National Center for Health Statistics. Retrieved from http://www.cdc.gov/nchs/data/nvsr/nvsr58/nvsr58_05.pdf

Page, R. L. (2007). Differences in health behaviors of Hispanic, white, and black childbearing women: Focus on the Hispanic paradox. Hispanic Journal of Behavioral Sciences, 29, 300-312. doi: 10.1177/0739986307304179.

Public Health Agency of Canada. (2008). Canadian perinatal health report, 2008 edition. Ottawa, ON: Author. Retrieved from http://www.phac-aspc.gc.ca/publicat/2008/cphrrspc/pdf/cphr-rspc08-eng.pdf 
Reid, J. (2007). CenteringPregnancy: A model for group prenatal care. Nursing for Women's Health, 11 (4), 382-388. doi:10.0000/j.1751-486X.2007.00914.x.

Selden, T. M. (2006). Compliance with well-child visit recommendations: Evidence from the medical expenditure panel survey, 2000-2002. Pediatrics, 118, e1766-e1778.

doi: 10.1542/peds.2006-0286.

Tankersley, J., \& Parsons, C. (2008). Immigration polarizes small-town America. Chicago Tribune. Retrieved fromhttp://articles.chicagotribune.com/2008-0925/news/0809242001_1_immigration-small-towns-new-complexion

U.S. Bureau of the Census. (1974). Statistical abstract of the United States (95th ed.). Washington, DC: Author. Retrieved fromhttp://www2.census.gov/prod2/statcomp/documents/1974-02.pdf

U.S. Bureau of the Census. (2010). The 2010 statistical abstract. Retrieved fromhttp://www.census.gov/compendia/statab/2010/files/racehisp.html

Womack, J. M. (2010). Safety and adherence: Issues that hinder childhood vaccinations: Scrutiny of recommended childhood vaccines continues to support their effectiveness. Journal of the American Academy of Physicians Assistants, 23 (1), 42-47.

Zhang, X., Joseph, K. S., \& Kramer, M. S. (2010). Decreased term and postterm birthweight in the United States: Impact of labor induction. American Journal of Obstetrics \& Gynecology, 203 (124), 124.e1-124.e7. doi: DOI: 10.1016/j.ajog.2010.03.044. 